\title{
INVESTIGATION OF TUNGSTEN HEAVY ALLOYS USING POWDER METALLURGY TECHNIQUE
}

\author{
Arafa S Sobha, Amr Adela, Abdelhay Mohameda, Ali Abd El-Atya, Mohamed Bhlola
}

Mechanical Engineering Department, Faculty of Engineering-Helwan, Helwan University, Cairo, Egypt.

Corresponding author: Ali Abd El-Aty, aliabdelaty@h-eng.helwan.edu.eg

\begin{abstract}
Recently, developing new alloys of Tungsten heavy (WHA) is the most important issue that researchers considered due to their wide applications of radiation protectors, vibration absorber, kinetic energy penetrators and heavy-duty electrical contacts. The present work shows 9 different Tungsten alloys with a variety of weight percent's from "Graphene" as a Nano- particle additive. The proposed alloys produced by minimizing manufacturing parameters by applying the Taguchi technique. In addition, this work used to relate the PowderMetallurgy (PM) parameters such as Sintering Temperature (ST) level, the weight \% of the added Nanoparticle of Graphene $(\mathrm{Gw})$ and the type of Process Control Agent (PCA) with the mechanical characteristics such as Young's modulus, modulus of Bulk, modulus of Shear, Poisson's number, Vickers hardness, Grain size , Relative Density. The results showed that specimen number 8 is given higher values of modulus of elasticity, reached 326.2 $\mathrm{GPa}$, bulk value of $255.64 \mathrm{GPa}$, and shear value of 126.7 GPa with PM preparation condition at $15000 \mathrm{C}$ sintering temperature, stearic acid as a process control agent (PCA) and $0.0 \% \mathrm{Wt}$. of Graphene.
\end{abstract}

Key words: Tungsten Alloy; powder metallurgy technique; Nano-particle of Graphene;

\section{INTRODUCTION}

Throughout these challenging times, developing new materials will promote new versions of products for new markets. Nowadays, people's culture is measured by the type of material and technology used for producing environment friendly products. Materials science plays a role in achieving society development [1].

The composite material is a promising family that contributes new developed solutions for aerospace, engineering structures, agriculture, and military applications [2]. The tremendous growth in using composite materials is due to the created properties that can be achieved from the mixing process of matrix phase materials and reinforcement materials embedded in a matrix phase. The bulk properties of the obtained composites are different than the properties of individuals. The achieved products also possess high quality and performance at a low manufacturing cost than other products of different materials families [3]. Besides, good resistant chemical and mechanical properties are obtained by different composite materials of polymer matrix $[6,7]$.

There are two different points of view to classify composite materials. The first class, according to matrix base such as composites of metallic matrices MMCs, composites of ceramics matrices $\mathrm{CMC}$, and composites of polymers matrices PMC. MMCs are a mixture of metals matrices such as Aluminum (Al), Magnesium $(\mathrm{Mg})$, Iron $(\mathrm{Fe})$, Cobalt $(\mathrm{Co})$ and Copper $(\mathrm{Cu})$ supported by ceramics reinforcements $(\mathrm{Pb}, \mathrm{W}$, and $\mathrm{Mo})$ [4]. However, metallic matrix composites are mixture of a ceramic's matrices and included segments of graphite and aramid fibers KEVLAR as dispersed phases [4]. However, polymers matrices PMCs are obtained from thermosetting or thermoplastic materials and put it in glass, carbon, steel, or Kevlar fibers as reinforced medium [5]. The second perspective class is based on the reinforcement features and geometry, such as laminate or particle and fibrous with random or preferred orientation [6]. In this investigation, a study was developed on tungsten heavy alloy WHA by adding graphene. WHAs are composite material types composed of spherical tungsten particles $90 \% \mathrm{~W} 7 \%$ Ni $3 \%$ Co [7]. This research is one of the trials investigate the effect of graphene addition to WHA, hoping to improve the mechanical characteristics. For Example, Zeinab et al., who developed a new process to produce tungsten heavy alloys of nano size that called reduction methodology as same as mechanical alloying approach [7]. However, a wide field of investigations can be found in the research that enhances the alloy's mechanical properties. For example, EDMONDS and JONES studied the toughness of the two composite alloys of tungsten, nickel and iron and compare the results by tungsten, nickel and copper. They found that the value of results is depend on the cooling rate of sintering temperature, which influence the values of strength of the existence of tungsten particles in the matrix [5-7]. Gong et al. investigated tensile, yield, and 
fracture strengths of three different WHAs. The results showed a strong influence of temperature on these mechanical properties at high levels [7]. Besides, Neua et al. studied the replacement of WHA as an alternative solution as plasma-facing material. The obtained results confirmed that WHA provides a useful and costeffective alternative [6]. This research is one of the trials investigate the effect of graphene addition to WHA, hoping to improve the mechanical properties. The proposed alloy was studied at different conditions and parameters, which improves the ductility and machinability. A design of experiment (DOE) technique using Taguchi method, has been applied in this work to optimize the properties of tungsten heavy alloys. Taguchi experimental design is an important tool to generate a systematic and accurate approach to obtain optimization of process. The method follows steps of tools such as signal to noise $(\mathrm{S} / \mathrm{N})$ ratio to obtain the optimum values of conditions and the values effective factors on main characteristics.

\section{DESIGN OF EXPERIMENTS}

The proposed work, a managed procedure was structured and produced by Taguchi approach to create robust experiments. Experiments were planned by using Taguchi's L9 (33) orthogonal array, which means three parameters in three levels (see Table 1). Normally in the case of three factors with three levels, 33 or 27 experiments needed to be performed according to full factorial design. Because of the large number of experiments resulting from many parameters needed to be optimized, a robust experimental design (Taguchi method) was applied. The usage of Taguchi approach will ensure the optimum solution of combined parameters and factors with robust experimental design. Table 2 lists the proposed experimental design by applying Taguchi method, where only nine experimental runs are proposed using an orthogonal array of L9, for optimized and robust experimental design. WHAs containing $90 \mathrm{wt} . \%$ of $\mathrm{W}, 7 \mathrm{wt} . \%$ of $\mathrm{Ni}$ and $3 \mathrm{wt} . \% \mathrm{Co}$ with different graphene contents $(0.0,0.25$, and 0.50 $\mathrm{wt} \%)$ were manufactured by powder metallurgy process according to the experiments design using the Taguchi approach.

Table 1. Levels of factors selected for the experiments

\begin{tabular}{|c|l|c|c|c|}
\hline Symbol & Parameters & \multicolumn{3}{|c|}{ Levels } \\
\cline { 3 - 5 } A & $\begin{array}{l}\text { Process } \\
\text { Control Agent } \\
(\text { PCA) }\end{array}$ & Wax & $\begin{array}{c}\text { Stearic } \\
\text { Acid }\end{array}$ & $\begin{array}{c}\text { Mineral } \\
\text { Oil }\end{array}$ \\
\hline B & $\begin{array}{l}\text { Sintering } \\
\text { temp. }\left({ }^{\circ} \mathrm{C}\right)\end{array}$ & 1450 & 1475 & 1500 \\
\hline C & $\begin{array}{l}\text { Graphene, } \\
\text { wt.\% }\end{array}$ & 0.00 & 0.25 & 0.50 \\
\hline
\end{tabular}

Table 2. The proposed experimental Conditions

\begin{tabular}{|c|c|c|c|}
\hline $\begin{array}{c}\text { Sample } \\
\text { number }\end{array}$ & $\begin{array}{c}\text { Sintering } \\
\text { temperature }\end{array}{ }^{\circ} \mathrm{C}$ & $\begin{array}{c}\text { Process } \\
\text { control } \\
\text { agent }\end{array}$ & $\begin{array}{c}\text { Graphene } \\
\%\end{array}$ \\
\hline 1 & 1450 & Wax & 0.0 \\
\hline 2 & 1450 & $\begin{array}{c}\text { Stearic } \\
\text { acid }\end{array}$ & 0.25 \\
\hline 3 & 1450 & $\begin{array}{c}\text { Mineral } \\
\text { Oil }\end{array}$ & 0.50 \\
\hline 4 & 1475 & Wax & 0.25 \\
\hline 5 & 1475 & $\begin{array}{c}\text { Stearic } \\
\text { acid }\end{array}$ & 0.50 \\
\hline 6 & 1475 & $\begin{array}{c}\text { Mineral } \\
\text { Oil }\end{array}$ & 0.0 \\
\hline 7 & 1500 & Wax & 0.50 \\
\hline 8 & 1500 & $\begin{array}{c}\text { Stearic } \\
\text { acid }\end{array}$ & 0.0 \\
\hline 9 & 1500 & $\begin{array}{c}\text { Mineral } \\
\text { Oil }\end{array}$ & 0.25 \\
\hline
\end{tabular}

\section{EXPERIMENTAL PROCEDURES}

Powder of Tungsten of size (99.95 pct, $60 \mu \mathrm{m}$ ) purchased from Buffalo Tungsten, INC., USA, powder of nickel $(99.99$ pct, 0.5:2 $\mu \mathrm{m})$ delivered from Sigma-Aldrich, China, cobalt powder (99.6 pct, $0.5: 2 \mu \mathrm{m})$ delivered from Jin Sheng International Industrial LTD, China, and graphene powder (99.99 pct, $10 \mathrm{~nm}$ ) obtained from chemical supply materials, China, were used in this study. The mixture of powders of $\mathrm{W}, \mathrm{Ni}, \mathrm{Co}$, and graphene with different ratios were milled by ball together for 360 minutes to get consistent reduced sizes of to enhance sintering performance. The milling operation of dry ball was performed using a home-made milling machine with a constant rotational speed of $120 \mathrm{rpm}$ and a jar made of stainless steel. The used balls were diameters of $10 \mathrm{~mm}$ with a ball to powder mass ratio of $3: 1$. Following the milling process, all investigated powders of the desired chemical compositions were mixed with a lubricant in a cylindrical tank mixer for 6 hours to ensure homogenization.

Three types of lubricant, namely; paraffin lubricant wax, stearic acid, and mineral oil, were added to the investigated powders with 1.0 wt.\%. The mixtures were then compacted into a short prismatic pellet of $15 \times 12 \mathrm{~mm}$ base cross-section and $10 \mathrm{~mm}$ height at room temperature under the compaction pressure of $315 \mathrm{MPa}$ using a hydraulic single action vertical press. The green compacts were then maintained at sintering temperature of 1450,1475 , and $1500{ }^{\circ} \mathrm{C}$ in a vacuum furnace for 60 minutes using the rate of heating of $3{ }^{\circ} \mathrm{C} / \mathrm{min}$ below $850{ }^{\circ} \mathrm{C}$ and $5{ }^{\circ} \mathrm{C} / \mathrm{min}$ above $850{ }^{\circ} \mathrm{C}$. The details of the sintering cycle used in this investigation is depicted in Figure 1. 


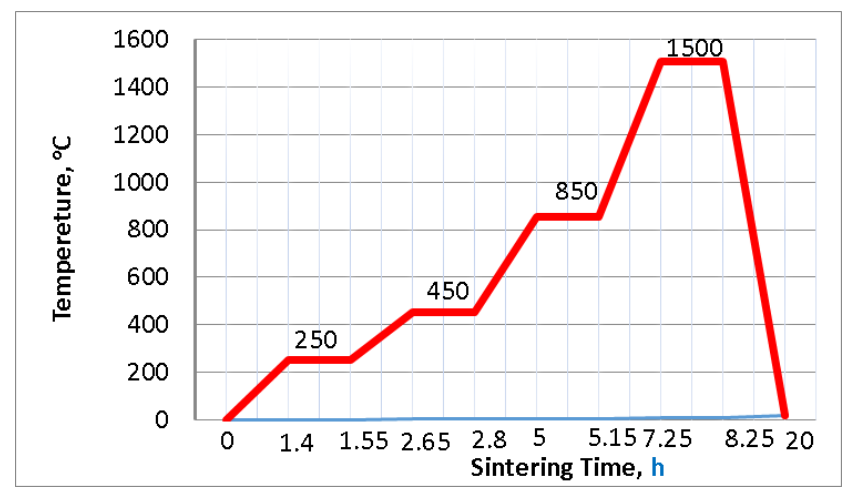

Fig. 1. Sintering cycle process

Extensive investigations of metallographic were performed to evaluate the microstructure of the manufactured tungsten heavy alloys using a scanning electron microscope (SEM) Model Quanta 250 FEG (Field Emission Gun) attached with EDX Unit (Energy Dispersive X-ray Analyses), with accelerating voltage $30 \mathrm{KV}$ and magnification of $14 \mathrm{X}$ up to $1000000 \mathrm{X}$. The sintering process produces materials of density can be evaluated by Archimedes theory based on water floating liquid. The actual and theoretical densities of mixed phases were calculated using the mixture's rule according to equations (1) and (2), respectively.

$$
\rho_{\text {actual }}=\left(\frac{m_{a}}{m_{a}-m_{w}}\right) * \rho_{w}
$$

where, $m_{\mathrm{a}}$ and $\mathrm{m}_{\mathrm{w}}$ are the sample weights in air and water $(\mathrm{g})$, and $\rho_{\mathrm{w}}(\mathrm{g} / \mathrm{cm} 3)$ is the density of distilled water $\left(1 \mathrm{~g} / \mathrm{cm}^{3}\right)$, respectively.

$$
\rho_{\text {th }}=F_{\mathrm{v} 1 \rho 1}+F_{\mathrm{v} 2 \rho 2}+F_{\mathrm{v} 3 \rho 3}+F_{\mathrm{v} 4 \rho 4}\left(\mathrm{~g} / \mathrm{cm}^{3}\right)
$$

where; the sum of volume fractions $\mathrm{F}_{\mathrm{V} 1}, \mathrm{~F}_{\mathrm{V} 2}, \mathrm{~F}_{\mathrm{V} 3}$, and $\mathrm{F}_{\mathrm{V} 4}$ equal 1 , and $\rho_{1}, \rho_{2}, \rho_{3}$ and $\rho_{4}$ are the densities of phases $1,2,3$, and 4 , respectively.

The investigated materials' hardness values were evaluated by the average of 5 records over the specimens' cross-section surface using the Vickers hardness test (model HWDM-7) at a load of $20 \mathrm{Kg}$ for 15 seconds holding time. The compressive properties were also evaluated by using computerize universal tensile test (UTM-50KNmodel) machine. Conditions such as $0.1 \mathrm{~mm} / \mathrm{min}$ movable travel speed with $20 \mathrm{KN}$ maximum load scale were used. The tested specimens' resultant strain values were measured using foil type strain gauges (HBM Type 3/120LY11) with gauge factor $1.98 \pm 1 \%$ in conjunction with digital - fourchannel strainmeter ( $\mathrm{P} 3-$ model).

\section{RESULTS AND DISCUSSION}

\subsection{Microstructure evolution}

Figure 2 shows the SEM micrographs of 9 samples of sintering process of "90W-7Ni-3Co" WHAs listed in
Table 2. The dark grey areas in these micrographs represent the binder material, while the white grey particles are the pure tungsten and the black color represented the graphene, as shown by the arrows. It is noticed that the microstructures are homogeneous.

To ensure that the resultant structure of proposed alloys contains the assigned values, the values are measured by EDX (Energy-dispersive X-ray) method (see Figure 3). Table 3 list the observed weight percentage of the main alloying elements based on the photograph for specimens No.1 and 3.

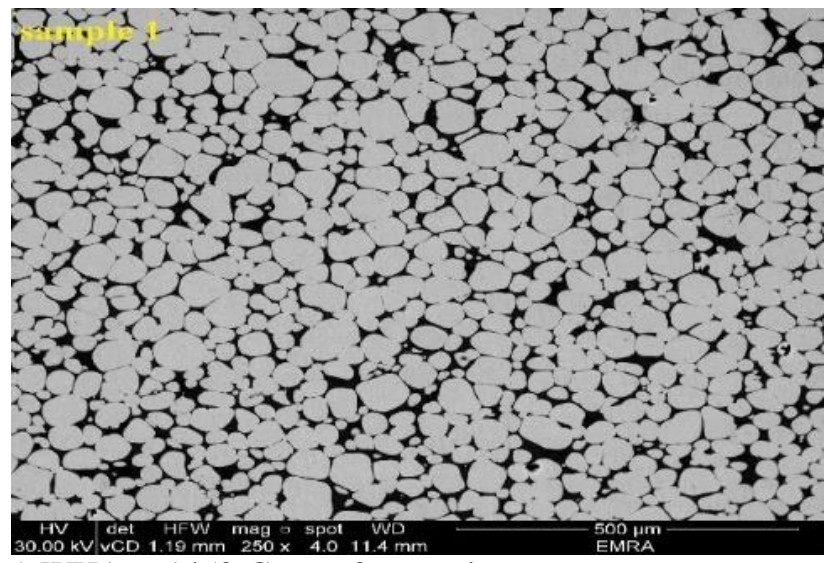

a) WHA at $1450^{\circ} \mathrm{C}$-wax-0\% graphene

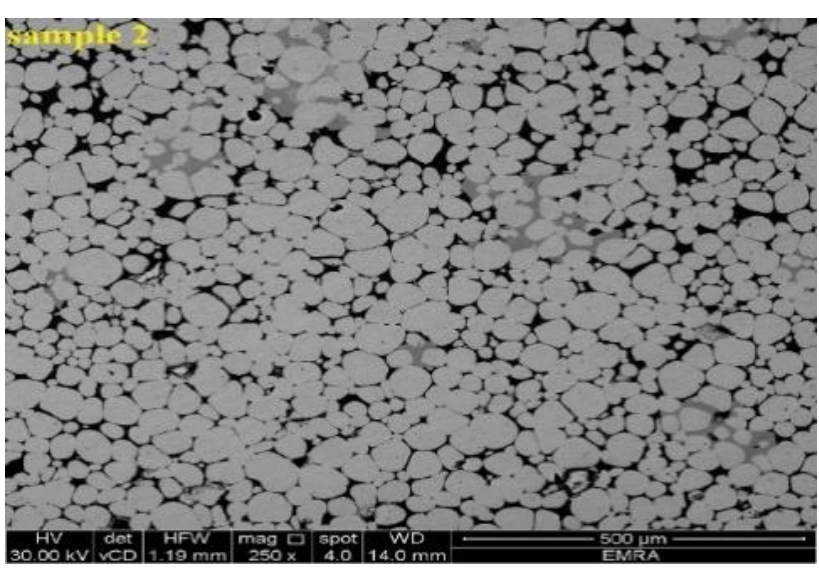

b) WHA at $1450^{\circ} \mathrm{C}$-stearic acid- $0.25 \%$ graphene

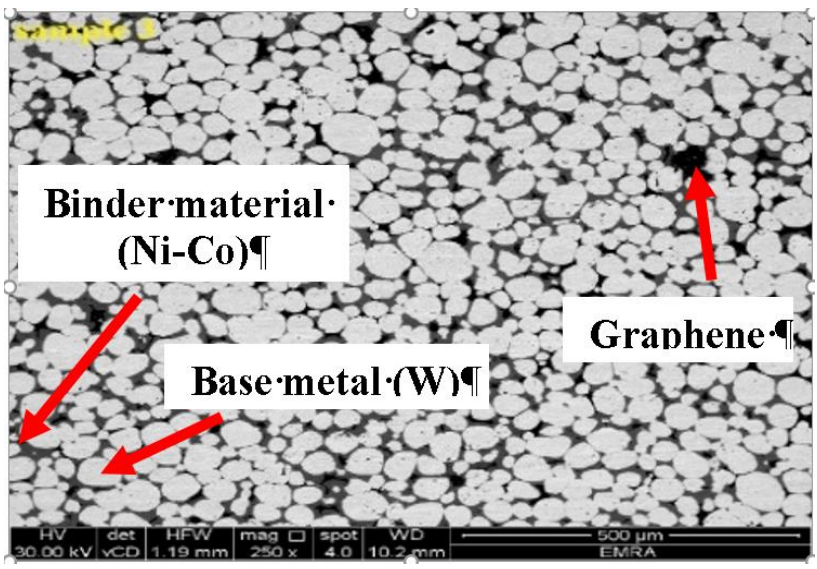

c) WHA at $1450^{\circ} \mathrm{C}$-mineral oil-0.5\% graphene 


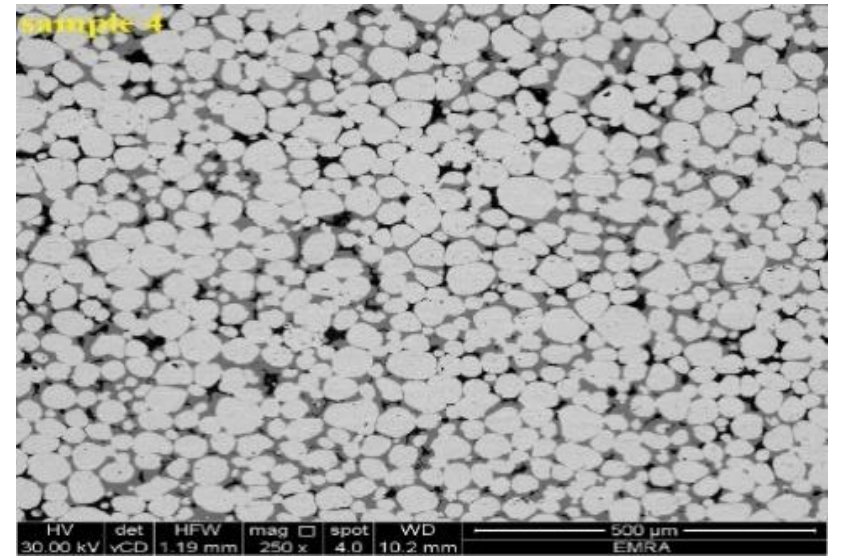

d) WHA at $1475^{\circ} \mathrm{C}$-wax- $0.25 \%$ graphene

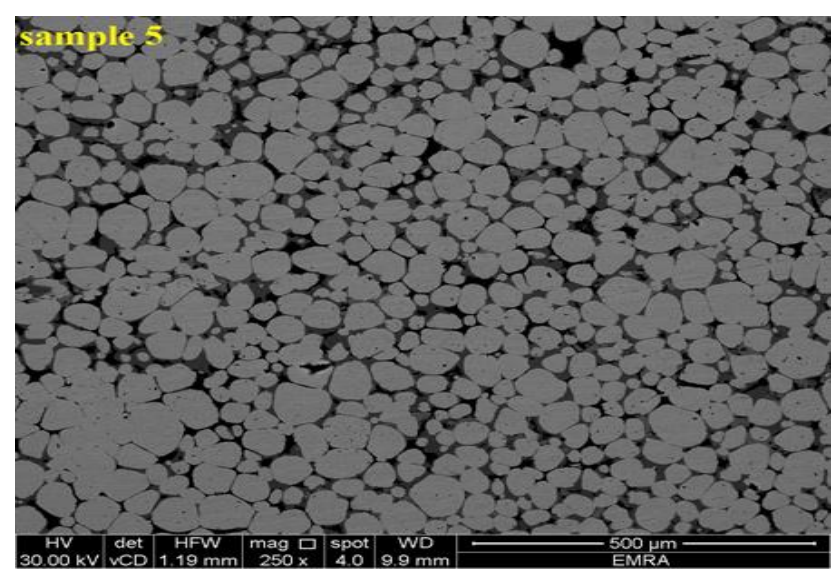

e) WHA at $1475^{\circ} \mathrm{C}$-stearic acid-0.5\% graphene

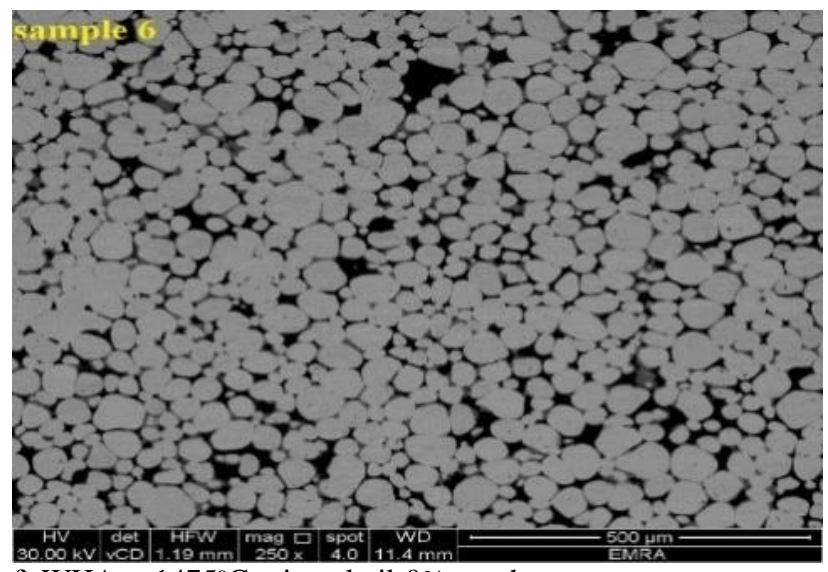

f) WHA at $1475^{\circ} \mathrm{C}$-mineral oil-0\% graphene

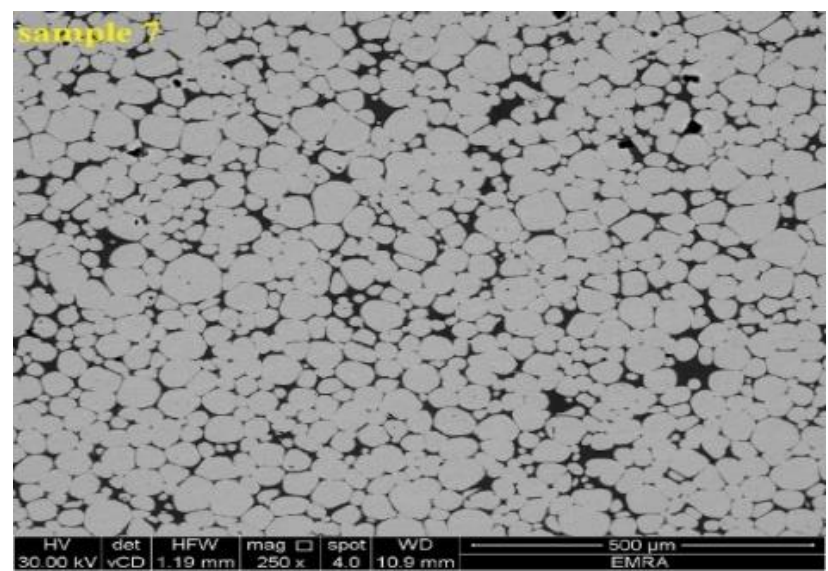

g) WHA at $1500{ }^{\circ} \mathrm{C}$-wax- $0.5 \%$ graphene

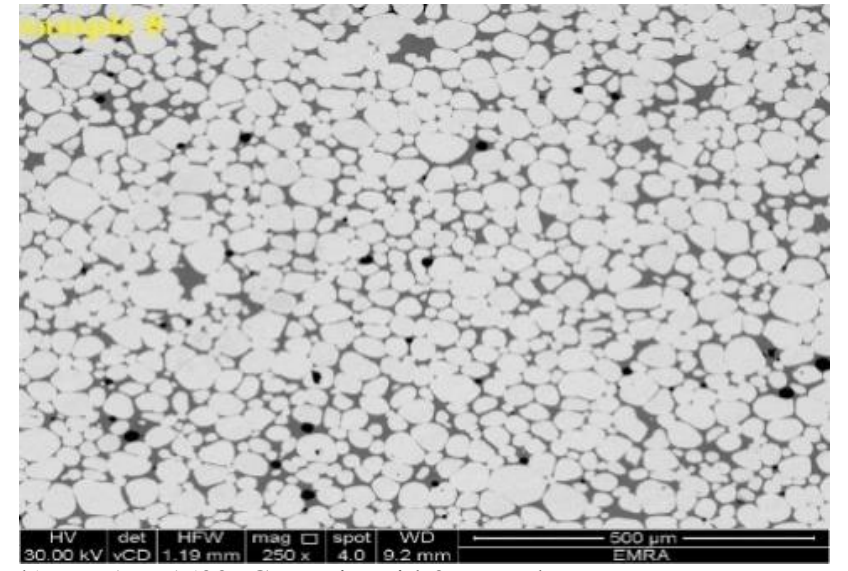

h) WHA at $1500{ }^{\circ} \mathrm{C}$-stearic acid-0\% graphene

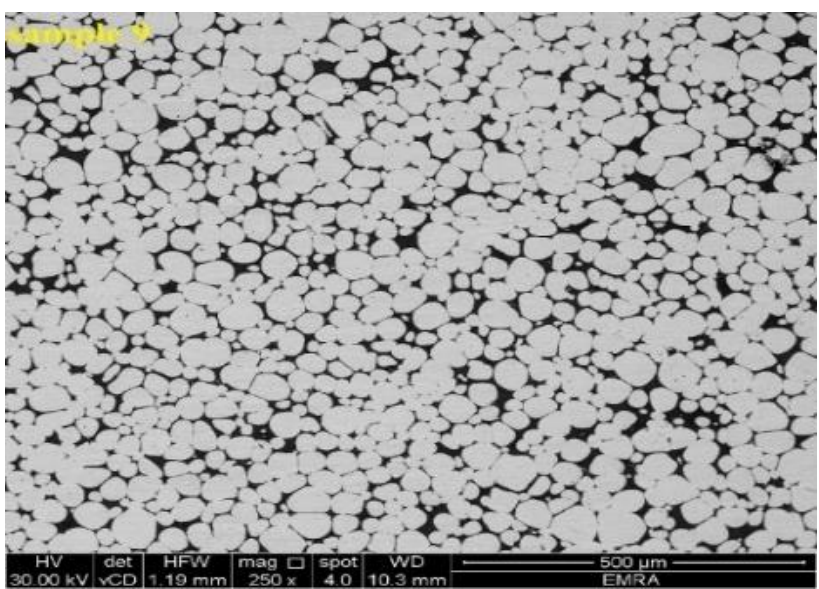

i) WHA at $1500{ }^{\circ} \mathrm{C}$-mineral oil-0.25\% graphene

Fig. 2. SEM micrograph of "90W-7Ni-3Co" Nine samples
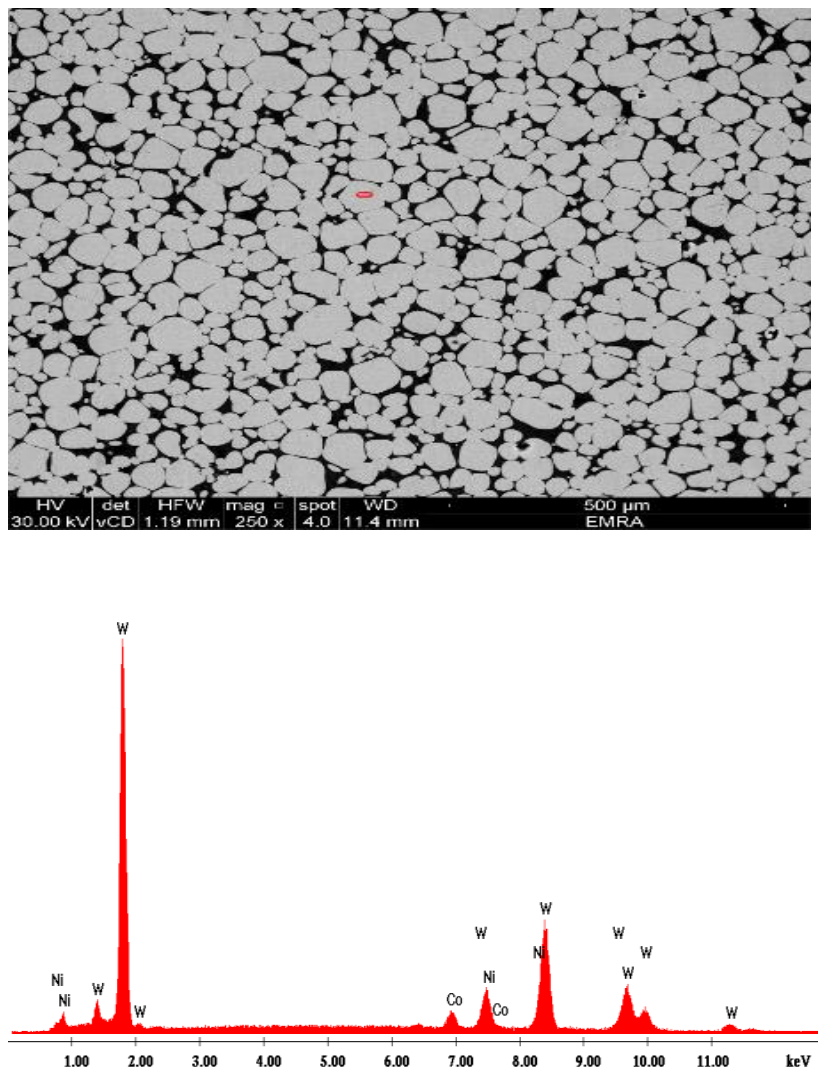

a) 

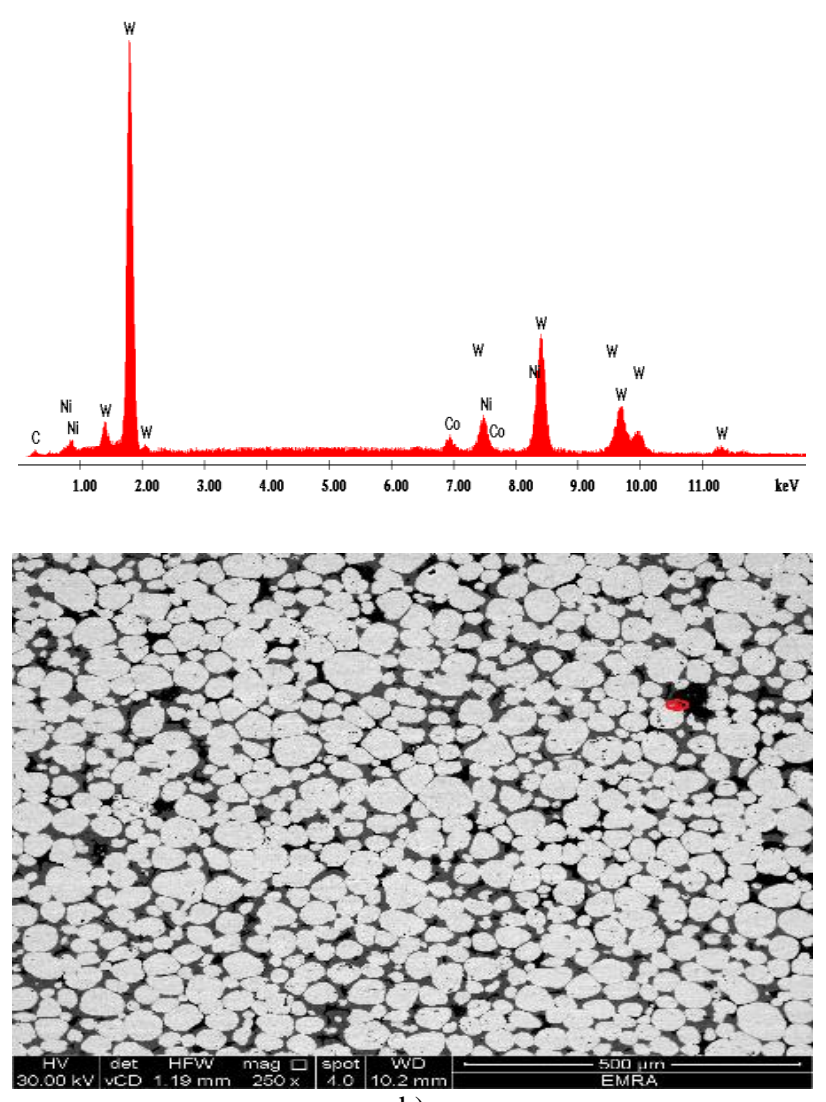

b)

Fig. 3. EDX analysis for samples a) No.1; b) No.3

Table 3. Main elements of samples no. 1 and 3

\begin{tabular}{|c|c|c|c|c|c|c|}
\hline & \multicolumn{4}{|c|}{ Proposed Alloy "90W-7Ni-3Co" } \\
\hline Elements & \multicolumn{3}{|c|}{ Specimen No.1 } & \multicolumn{3}{c|}{ Specimen No.3 } \\
\cline { 2 - 7 } & Actual & Obs. & $\begin{array}{c}\text { Variation } \\
\text { \% }\end{array}$ & Actual & Obs. & $\begin{array}{c}\text { Variation } \\
\text { \% }\end{array}$ \\
\hline $\mathrm{W} \%$ & 90 & 87.72 & 2.53 & 90 & 87.60 & 2.66 \\
\hline $\mathrm{Ni} \%$ & 7 & 8.49 & -21.28 & 7 & 6.63 & 5.29 \\
\hline $\mathrm{Co} \%$ & 3 & 3.79 & -23.66 & 3 & 2.55 & 15 \\
\hline $\mathrm{G} \%$ & zero & zero & zero & 0.5 & 3.22 & -544 \\
\hline Total \% & 100 & 100 & zero & 100 & 100 & zero \\
\hline
\end{tabular}

\subsection{Sintered densities results}

The results of relative densities of the alloys are summarized in both Table 4 and Figure 4 . The results showed that the theoretical density is largely than actual density. The smallest value of actual density of the specimen number 3 with graphene content $0.5 \%$, and the highest value of actual density of the specimen number 8 with zero graphene content. The Decreasing of actual density than theoretical density, caused due to two reasons, the first one is sintering process which led to shrinkage in the specimen due to sintering mechanism where during the cold compaction there is generated friction between particles led to small contact at a point, this point contact is then grow during the sintering and form the" neck", this make the pores between particles reduce in size and finally the formation of grain boundaries. The second reason is increasing the graphene content that led to reduction of actual density due to the density of graphene is lower than the tungsten element.

Table 4. Comparison between actual and theoretical densities

\begin{tabular}{|c|c|c|c|}
\hline $\begin{array}{c}\text { Specimen } \\
\text { number }\end{array}$ & $\begin{array}{c}\text { Actual } \\
\text { density } \\
\left(\mathrm{Kg} / \mathrm{m}^{3}\right)\end{array}$ & $\begin{array}{c}\text { Theoretical } \\
\text { density } \\
\left(\mathrm{Kg} / \mathrm{m}^{3}\right)\end{array}$ & $\begin{array}{l}\text { Relative } \\
\text { variation in } \\
\text { density, \% }\end{array}$ \\
\hline 1 & 15172.5 & 17246.7 & \pm 0.8797 \\
\hline 2 & 14477.9 & 16957.5 & \pm 0.8538 \\
\hline 3 & 13287.4 & 16679.2 & \pm 0.7966 \\
\hline 4 & 14509.9 & 16957.5 & \pm 0.8557 \\
\hline 5 & 13971.7 & 16679.2 & \pm 0.8377 \\
\hline 6 & 14574.4 & 17246.7 & \pm 0.8451 \\
\hline 7 & 13819.1 & 16679.2 & \pm 0.8285 \\
\hline 8 & 15213.9 & 17246.7 & \pm 0.8821 \\
\hline 9 & 13951.4 & 16957.5 & \pm 0.8227 \\
\hline
\end{tabular}

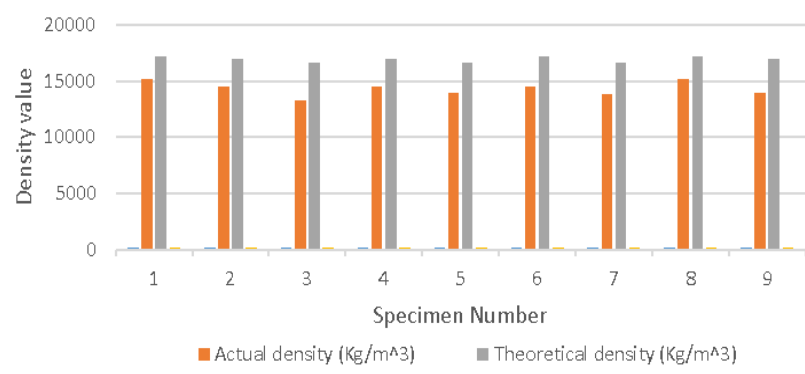

Fig. 4. Histogram of relative and theoretical densities of investigated alloys

Taguchi experimental design was used to maximize the properties of WHAs. The main effects plot for $\mathrm{S} / \mathrm{N}$ ratio of sintered density is shown in Figure 5. The figure is constructed to explain the influence of factors and their levels on the density. It is obvious that the control factors namely; process control agent at level 1 (wax), sintering temperature at level 1(1450 ${ }^{\circ} \mathrm{C}$ ) and graphene percentage at level 1 (0 wt. \%) provided the best response. Also Taguchi shows that the most significant factors as follow (process control agent, sintering temperature, graphene percentage wt. $\%$ ) respectively.

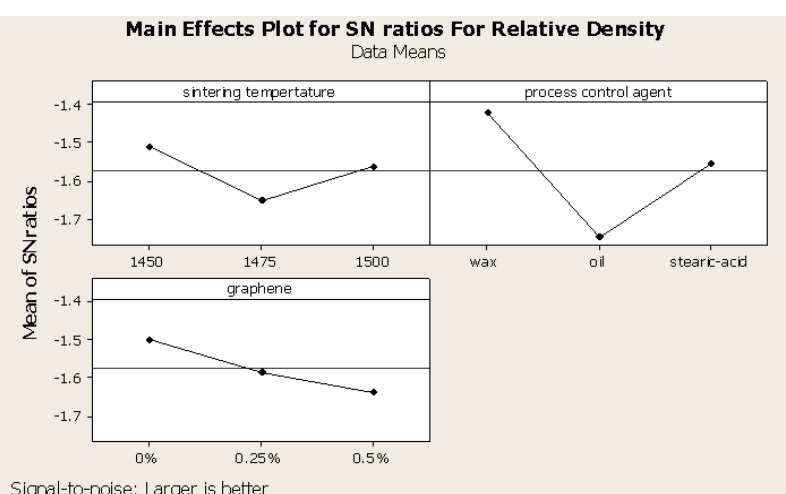

Fig. 5. Mean of $\mathrm{S} / \mathrm{N}$ ratios for density of samples versus levels of input parameters

\subsection{Hardness results}

Measured Vickers hardness for different tested alloys 
are tabulated in Table 5. The $\mathrm{S} / \mathrm{N}$ response graph for hardness is shown in Figure 6. According to this graph it is obvious that higher values of hardness is taking place at $1475 \mathrm{oC}$ sintering temperature, with stearic acid, and 0 wt.\% of graphene. This result is attributed relatively to the smaller size of grain (i.e. 42 microns) for the tungsten heavy alloy as shown in the microstructure micrographs. Also it accounts for high Vickers hardness number due to the graphene distribution uniformity in microstructure. Also Taguchi shows that the most significant factors as follow (sintering temperature, process control agent, graphene percentage $\mathrm{wt} \%$ ) respectively.

Table 5. Measured hardness by Vickers test

\begin{tabular}{|c|c|c|c|}
\hline $\begin{array}{c}\text { Specimen } \\
\text { No. }\end{array}$ & $\begin{array}{c}\text { Average } \\
\text { Vickers } \\
\text { hardness } \\
(\mathrm{Hv})\end{array}$ & $\begin{array}{c}\text { Average } \\
\text { grain size } \\
(\mu \mathrm{m})\end{array}$ & $\begin{array}{c}\text { Actual } \\
\text { density } \\
\left(\mathrm{Kg} / \mathrm{m}^{3}\right)\end{array}$ \\
\hline 1 & 339 & 42 & 15172.53 \\
\hline 2 & 379 & 40 & 14477.91 \\
\hline 3 & 301 & 44 & 13287.37 \\
\hline 4 & 352 & 48 & 14509.98 \\
\hline 5 & 379 & 42 & 13971.74 \\
\hline 6 & 360 & 45 & 14574.44 \\
\hline 7 & 317 & 37 & 13819.11 \\
\hline 8 & 323 & 36 & 15213.95 \\
\hline 9 & 289 & 38 & 13951.39 \\
\hline
\end{tabular}

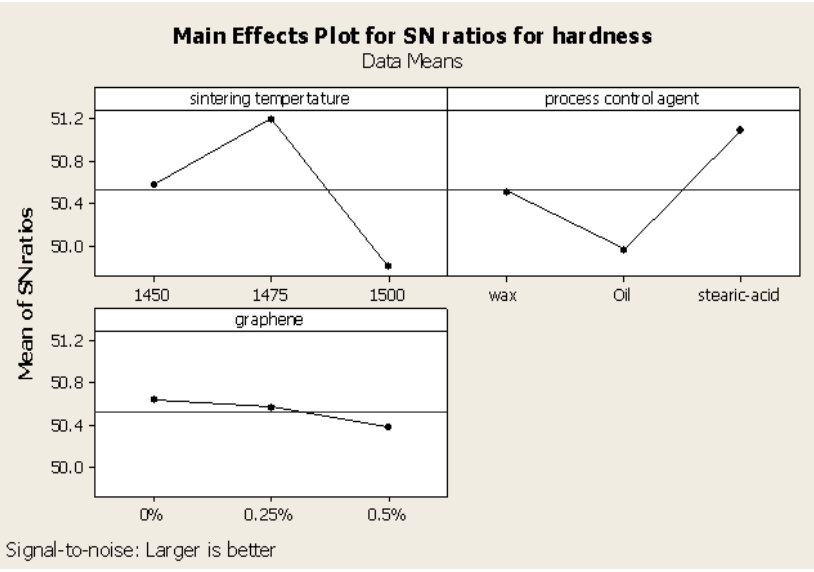

Fig. 6. The Taguchi SN- index for hardness of tested alloys

\subsection{Compressive properties}

\subsubsection{Elastic modulus}

The main effects plot for $\mathrm{S} / \mathrm{N}$ ratio of modulus of elasticity is shown in Figure 7. The figure is constructed to obvious the relationship between factors and their values on the modulus of elasticity. It is obvious that the control factors namely; process control agent at level 3 (stearic acid), sintering temperature at level $2\left(1475{ }^{\circ} \mathrm{C}\right)$ and graphene percentage at level 1 ( 0 wt.\%) provided the best response.

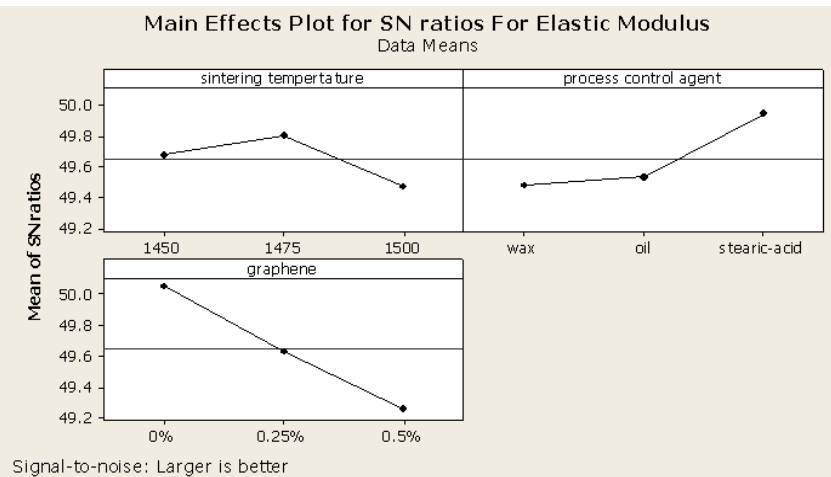

Fig. 7. The Taguchi SN- index for modulus of elasticity of the proposed alloys

\subsubsection{Poisson Ratio}

It's well known for design purposes, smaller Poisson ratio is preferred in contrast for metal forming requirement of higher values. Taguchi $\mathrm{SN}$ - index of Poission ratio is shown in Figure 8. It implies that sintering temperature of $14750 \mathrm{C}$ with stearic acid as process control agent and value of $0.00 \% \mathrm{Wt}$ graphene were led to lower such ratio.

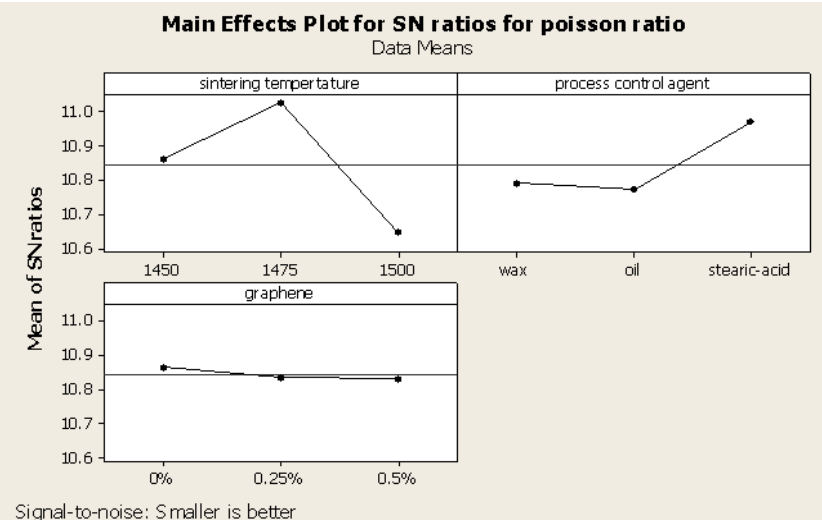

Fig. 8. The Taguchi SN- index for Poisson ratio of tested alloys

Taguchi shows that the most significant factors as follow (sintering temperature, process control agent, , graphene percentage wt $\%$ ) respectively.

\section{CONCLUSIONS}

In this investigation, it is concluded that the addition of graphene has no significant effect on both of the modulus of elasticity and hardness. In the other hand the addition of graphene has enhancement effect on bulk modulus and the shearing modulus. Taguchi technique also can be ranking the influence of the parameter that affected on the studied output response. It can also be found that WHAs properties such as, hardness, Poisson ratio and grain Size influenced by sintering temperature. Among the three factors tested, it was concluded that the PCA has the strongest effect in producing a denser structure. Process control agent by Stearic acid improved both modulus of elasticity and hardness values. 


\section{REFERENCES}

1. Mason, W.P., McSkimin, H.J.: (1974), Attenuation and scattering of high frequency sound waves in metals and glasses. J. Acoust. Soc. Am 19, 464-473

2. Palanichamy, P., Mathew, M.D., Latha, S., Jayakumar, T., Bhanu Sankara Rao, K.,Mannan, S.L., Raj, B.:(2001), Assessing microstructural changes in alloy 625 using ultrasonic waves and correlation with tensile properties. Scr. Mater. 45, 1025-1030

3. Murthy, G.V.C., Ghosh, S., Das, M., Das, G., Ghosh, R.N. (2008), Correlation between ultrasonic velocity and indentation-based mechanical properties with microstructure in Nimonic 263. Materials Science and Engineering A, 488, pp. 398-405

4. Hsia S.-Y., Chou, Y.-T., (2015), Assessing the hardness of quenched medium steel using an ultrasonic nondestructive method, Advances in Materials Science and Engineering, 3, 1-8.

5. Aghaie-Khafri M., Honarvar F., Zanganeh S., (2012), Characterization of Grain Size and Yield Strength in AISI 301 Stainless Steel Using Ultrasonic Attenuation Measurements, Journal of nondestructive evaluation, 31, 191-196.

6. Hamidnia M., Honarvar F., (2012), Measurement of elastic properties of AISI 52100 alloy steel by ultrasonic nondestructive methods, J. Mech. Mater. Struct. Journal of Mechanics of Materials and Structures, 7, 951-961.

7. Rayes M. M. E., El-Danaf E. A., Almajid A. A., (2014), Ultrasonic Non-Destructive Characterization of Power Plant Steel, 199-208.
Received: September 5, 2021 / Accepted: December 15, 2021 / Paper available online: December 20, 2021 (C) International Journal of Modern Manufacturing Technologies. 